\title{
EST patent granted for human kinase homologs
}

In November 1998, the US Patent and Trademark Office (PTO; Washington, DC) awarded Incyte Pharmaceuticals (Palo Alto, CA) the first patent for an expressed sequence tag (EST) — a gene fragment containing partial cDNAs of expressed mRNAs-claiming polynucleotides that identify and encode novel human kinases. The first of its kind, this patent could lead to new licensing revenue streams for Incyte and other companies with EST patent claims pending. However, there is concern that the language of the patent enables the patentee to claim not only the EST but also the full gene of which it is part, and it is unclear how licensing tangles resulting from patents on multiple ESTs from the same gene will be resolved. In addition, academic researchers complain that licensing ESTs as research tools will significantly slow genomic research. Although the US National Institutes of Health (NIH) has so far chosen to publish its ESTs, there is speculation as to how long it will be before public databases are commercialized.

Satisfying the PTO's "written description" requirement for invention (Nat. Biotechnol. 16:711, 1998), the Incyte patent (No. $5,817,479)$ claims the novel "nucleic acid sequences" (not known in the public domain) and their use as DNA probes to obtain the full-length human kinase cDNA described in the patent.

In response to the Incyte patent, Francis Collins, director of the US National Human Genome Research Institute (Bethesda, MD), remarked at a meeting at the beginning of December that the broad issuing of this EST patent "is a disturbing turn of events." "While the language is a little ambiguous," says Collins, "it is disturbing that [the patent] seems to move in the direction of the broad claim, where the EST entitles you to claim the entire full-length cDNA and perhaps the whole gene."

Specifically, the Incyte patent claims an expression vector comprising polynucleotides from a group of 44 ESTs. The legal and biotechnology communities are concerned that interpretation of the word "comprising" suggests broader patent rights not only to the EST sequence but also to adjacent sequences or even the full-length gene.

The legal determination of scope of this claim (for this first EST patent and others pending) is expected to directly impact genomics companies that are in the process of identifying full-length genes without the patent rights to ESTs or SNPs (single-

Debra Robertson is a freelance writer working in San Diego, CA. nucleotide polymorphisms). However, Roy Whitfield, CEO of Incyte, says only that "This EST patent is no different from any of the other patents submitted by Incyte; its scope and validity will be determined by law."

Jack Tribble, head of Merck's (Wilmington, DE) biotechnology patent group, points out another problem. "If there are multiple patents on ESTs within a wellknown gene, one may require license for [all] those ESTs so you can use the full-length gene," he says. "This [sort of] dispute will have to be handled in court." He suggests that the US patent office may have to switch to closed language such as "consisting of" or "consisting essentially of" in order to limit patent rights to the sequence of an EST only.

Meanwhile, academic scientists are worried that limiting either the use of ESTs with license requirements or sequestering the identity of ESTs required early in the genehunting process in commercial databases will severely slow medical research. Bruce Alberts, president of the National Academy of Sciences, writes in a letter to the PTO that "our concern is that patents are being used in ways that create obstacles to conquering human diseases."

Whitfield, whose company offers nonexclusive licensing of ESTs, emphatically points out that ESTs are research tools, "like PCR," the use of which is also protected by patent rights and requires a license. "Show me one example as to how the development of this and other research tools has slowed research," he challenges.

It may be that the policy of the NIH to publish EST sequences has postponed the inevitable decisions related to the scope of the claims for this and future EST patents. But Craig Venter of Celera, which operates a for-profit database with published genomes freely available, points out "a very dangerous trend, starting in Europe, of publicly supported databases turning into commercial databases." Venter warns that "it would not take a whole lot for Congress to turn around and say that GenBank would start charging for service."

Debra Robertson

\section{Companies chase money in and out of the Eurozone}

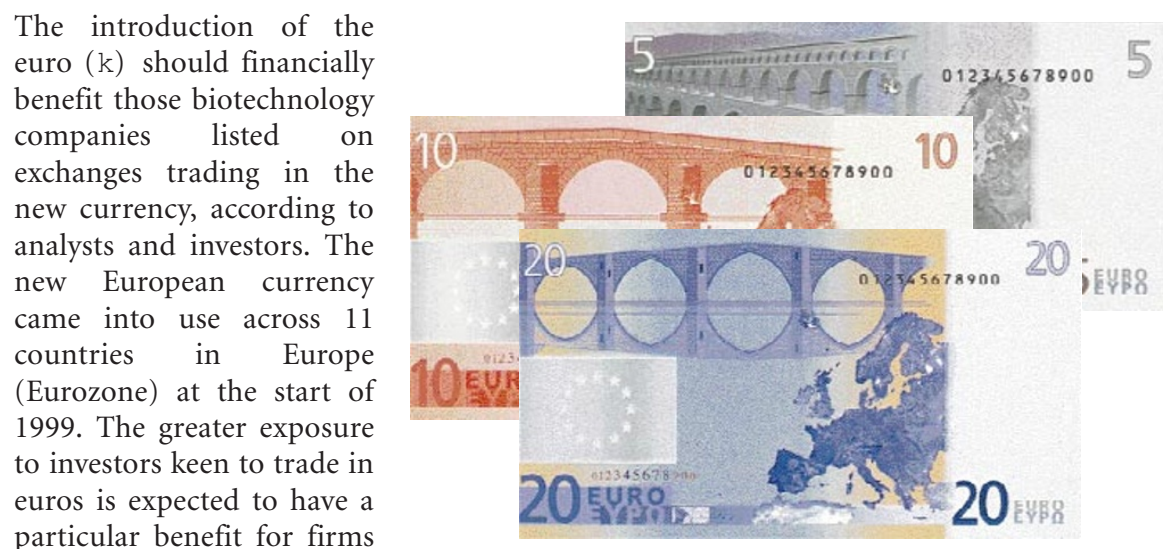
particular benefit for firms listed in the smaller Eurozone states that previously traded in currencies such as the Dutch guilder and Belgian franc that are less internationally recognized. Some observers predict that the electronic trading exchange, Easdaq, will become a hot spot in Europe for raising money. Easdaq was trading in all European currencies, but all its listed companies based in the Eurozone now trade in Euros. It can also offer non-Eurozone firms a Euro listing. Analysts and investors believe the combination of the pan-European currency and the
pan-European investor base could be a winning formula.

Stephen Parker, a director of Apax Partners (London), an investment group targeting hi-tech industries including biotechnology, believes it will be easier for nonEuropean investors to follow companies if they are trading in Euros. "For investors outside Europe, one thing that got in the way in the past was dealing with 20 or so different currencies," he says. Focusing on just the one currency should help investors make more 